\section{Residential care in Italy}

\author{
National survey of non-hospital facilities \\ G. DE GIROLAMO, A. PICARDI, R. MICCIOLO, I. FALLOON, A. FIORITTI \\ and P. MOROSINI for the PROGRES Group
}

Twenty-four years ago Law 180 initiated the phasing-out of mental hospitals in Italy; updated information concerning the architecture of the current mental health system in Italy, including the in-patient bed policy, can be found elsewhere (de Girolamo \& Cozza, 2000). When Law 180 was enacted in 1978, there were 78538 beds in public mental hospitals. Patients who require long-term residential care are now catered for by non-hospital residential facilities (NHRFs). Information about the quantity and quality of these facilities is sparse. This study reports the first phase of the Progetto Residenze (PROGRES) residential care project, funded by the Italian National Institute of Health. The aim of this national survey was to obtain data on demographic and clinical characteristics of residents, staffing arrangements, regional provision of NHRFs, and discharge rates. In addition, the study aimed to clarify relationships between the availability of residential places and the provision of other mental health resources.

\section{METHOD}

All 21 Italian regions participated. A census was made of all NHRFs with four or more residential places; basic information on small residences with only one to three beds was also obtained. The facilities included those defined as 'group homes', 'supervised apartments' and 'hostels'.

\section{Data collection}

Each region appointed a coordinator, who organised and supervised data collection. Information about the number and location of all public and private NHRFs was obtained from the 21 regional ministries of health and then from each of the 224 departments of mental health throughout the country. The manager of each NHRF completed a structured interview, drawn in part from the Royal College of Psychiatrists'
Mental Health Residential Care Study (Lelliott et al, 1996). The information was checked by the regional coordinators, who conducted further interviews when necessary.

\section{Statistical analysis}

Analysis focused on descriptive statistics. In addition, multiple logistic regression was used to identify variables associated with the probability of discharge (Breslow \& Day, 1980). The dependent variable was the presence or absence of discharges from each NHRF during 1999; facilities opened from 1999 onwards were excluded.

Poisson regression was used to analyse the relationship between the rate of residential beds in each region (number per 10000 inhabitants), the availability of other types of services, and two basic socio-economic indicators: number of unemployed per region, in millions of people, and overall regional income, in millions of euros (Breslow \& Day, 1987; Zheng \& Agresti, 2000). Figures used for this analysis were based on 1998 government statistics (de Girolamo \& Cozza, 2000), while the number of beds in private in-patient facilities was obtained from the national Ministry of Health; the socio-economic data are the official data for the corresponding year. The very small Valle d'Aosta region was combined with the neighbouring Piedmont region. All analyses were performed using SPSS, version 9.0 for Windows.

\section{RESULTS}

Throughout Italy there were 1370 NHRFs with at least four places, a total of 17138 beds, with an average of 12.5 beds in each. A further 125 NHRFs had only one bed, 108 had two, and 100 had three beds. These facilities were not included in subsequent analyses.

Overall, there were 2.98 residential beds for every 10000 inhabitants, with a large variability between regions; the variation between the region with the highest rate of NHRFs, Abruzzo (6.93 per $10000)$, and the region with the lowest rate, Campania (1.55 per 10000), was more than four-fold. Nineteen regions out of 21 had more than two residential beds per 10000 , which is the standard recommended by the National Mental Health Plan (Progetto Obiettivo, 1999). The average size of facilities also varied widely between regions, with 127 NHRFs (9.2\%) 
Table I Features and staffing of non-hospital residential facilities in Italy

n $\%$

\begin{tabular}{|c|c|c|}
\hline \multicolumn{3}{|l|}{ Intensity of care } \\
\hline Cover 24 hours & 1005 & 73.4 \\
\hline Cover $<24$ hours & 335 & 24.4 \\
\hline Assistance as needed & 30 & 2.2 \\
\hline \multicolumn{3}{|l|}{ Operated by } \\
\hline $\begin{array}{l}\text { NHS department of mental } \\
\text { health }\end{array}$ & 710 & 51.8 \\
\hline Voluntary organisations & 300 & 22.0 \\
\hline Private (for profit) & 194 & 14.1 \\
\hline Mixed public/private & 148 & 10.8 \\
\hline Other public organisations & 18 & 31.3 \\
\hline \multicolumn{3}{|l|}{ Full-time professionals employed' } \\
\hline Psychiatrists & 1522 & 8.2 \\
\hline Psychologists & 943 & 5.0 \\
\hline Specialised nurses & 5845 & 31.3 \\
\hline $\begin{array}{l}\text { Psychiatric rehabilitation } \\
\text { therapists }\end{array}$ & 300 & 1.6 \\
\hline Occupational therapists & 2085 & 11.2 \\
\hline Social workers & 826 & 4.4 \\
\hline Generic nurses & 3547 & 19.0 \\
\hline Other qualified personnel & 1813 & 9.7 \\
\hline Other non-qualified personnel & 1785 & 9.6 \\
\hline Total full-time staff & 11240 & 60.2 \\
\hline \multicolumn{3}{|l|}{ Director of the residence } \\
\hline Psychiatrist & 791 & 57.8 \\
\hline Psychologist & 150 & 10.9 \\
\hline Social worker & 79 & 5.8 \\
\hline Nurse & 36 & 2.7 \\
\hline Sociologist & II & 0.8 \\
\hline Other & 301 & 22.0 \\
\hline
\end{tabular}

NHS, National Health Service (Italy).

I. As a percentage of the 18666 total staff.

hosting more than 20 residents, the maximum recommended by the National Mental Health Plan. The occupancy rate was high (93\%), with little regional variation.

Table 1 summarises the main characteristics and staffing of the NHRFs. A high level of supervision was reported, with most facilities $(73.4 \%)$ having staff on-site 24 hours a day. Around half of these establishments had opened since January 1997. Most $(84.5 \%)$ catered exclusively for long-term patients, while $15.5 \%$ were also used occasionally for patients with acute illness episodes. Two-thirds were located in urban areas, and a quarter were rural; only $7.1 \%$ occupied the grounds of former mental hospitals. The relative majority
$(44.8 \%)$ were located in an independent building and $29.7 \%$ were in apartments. Most $(77.7 \%)$ received funding directly from the Italian National Health Service, and the local departments of mental health provided direct management for more than half $(51.8 \%)$.

\section{Staffing}

The 1370 NHRFs employed 18666 professionals, of whom $60 \%(n=11240)$ worked full-time (Table 1). The distribution of professional resources was variable. For example, 285 NHRFs (21\%) had no nurses, and almost half had no full-time nurses. Most $(57.8 \%)$ were directed by psychiatrists, while $22 \%$ had a coordinator who did not have mental health qualifications. Around $40 \%$ of staff had no specific professional qualification for working with patients with severe psychiatric conditions. The mean number of staff per NHRF was 13.7 (range 6.9-21.0); the mean number of full-time staff was 8.2

Table 2 Characteristics of residents in non-hospital residential facilities $(n=15943)$

\begin{tabular}{lrr}
\hline & $n$ & $\%$ \\
\hline Former places of residence & & \\
$\quad$ Patients never admitted to former mental hospital or forensic & 9319 & 58.5 \\
$\quad$ mental hospital & & \\
$\quad$ Former mental hospital residents & 6371 & 39.9 \\
$\quad$ Former forensic mental hospital patients & 253 & 1.6 \\
Clinical categories of residents & & \\
No current problems of alcohol or substance misuse & 13177 & 82.7 \\
Comorbid alcohol or substance misuse problems & 805 & 5.1 \\
Primary alcohol or substance misuse problems & 55 & 0.3 \\
Primary 'mental retardation' & 1593 & 10.0 \\
Other problems & 313 & 1.9 \\
Most numerous age group in each facility',2 & & \\
$\quad<40$ years & 434 & 31.8 \\
$40-59$ years & 681 & 49.8 \\
$>60$ years & 252 & 18.4 \\
Admissions in 199|1,3 & & \\
None & 334 & 24.4 \\
I-2 & 360 & 26.3 \\
$>2$ & 670 & 49.3 \\
Discharges in 19991,4 & & \\
None & 513 & 37.7 \\
I-2 2 & 429 & 31.5 \\
\hline
\end{tabular}

I. Figures refer to facilities, not to patients.

2. Data missing for 3 facilities.

3. Data missing for 6 facilities.

4. Data missing for 8 facilities. (range $0.6-15.0$ ). The overall ratio of patients to full-time staff was 1.42:1 (range 0.82-22.3)

\section{Patients}

At the census there were 15943 residents in the 1370 NHRFs, a mean of 11.6 per facility (Table 2). In $18 \%$ of the NHRFs there were only patients discharged from former mental hospitals, while the largest group of NHRFs $(43 \%)$ housed only patients who had never been admitted to a mental hospital. The majority of NHRF residents $(58.5 \%)$ had never before been admitted to a mental hospital or a forensic mental hospital, almost $40 \%$ had been admitted at least once to a mental hospital and $1.6 \%$ had been detained in a forensic mental hospital. Most residents $(82.7 \%)$ had no current problems of alcohol or substance misuse. 'Mental retardation' was the primary problem of around $10 \%$ of residents; half of these had come from mental hospitals. 
Table 3 Logistic regression: variables associated with no turnover of residents in non-hospital residential facilities in 1999 ( $n=1091$ )

\begin{tabular}{|c|c|c|c|c|c|}
\hline Variable & & Estimate & s.e. & $Z$ & $P$ \\
\hline Intercept & & -0.674 & 0.255 & -2.639 & 0.008 \\
\hline Former mental hospital patients & All v. not all & 0.828 & 0.195 & 4.241 & $<0.001$ \\
\hline Presence of full-time staff & No v. yes & 0.489 & 0.176 & 2.783 & 0.005 \\
\hline \multirow[t]{3}{*}{ Number of residents } & $6-10 v .1-5\left(p^{2}\right)$ & -0.843 & 0.325 & -2.596 & 0.009 \\
\hline & $I I-I 5$ v. I-5 (p3) & -1.915 & 0.529 & -3.620 & $<0.001$ \\
\hline & $>15$ v. I-5 (p4) & -2.873 & 0.737 & -3.900 & 0.000 \\
\hline \multirow[t]{2}{*}{ Most numerous age group } & $40-59$ years $v .<40$ years $(\mathrm{e} 2)$ & 0.221 & 0.319 & 0.692 & 0.489 \\
\hline & $>59$ years $v .<40$ years $(\mathrm{e} 3)$ & 0.287 & 0.413 & 0.695 & 0.487 \\
\hline Interaction between number of patients and most & p2.e2 & 0.748 & 0.412 & 1.816 & 0.069 \\
\hline \multirow[t]{5}{*}{ numerous age group } & p2.e3 & I.II5 & 0.522 & 2.138 & 0.032 \\
\hline & p3.e2 & 1.316 & 0.598 & 2.199 & 0.028 \\
\hline & p3.e3 & 1.903 & 0.719 & 2.648 & 0.008 \\
\hline & p4.e2 & 1.102 & 0.802 & 1.373 & 0.170 \\
\hline & p4.e3 & 2.728 & 0.851 & 3.207 & $<0.001$ \\
\hline
\end{tabular}

Table 4 Poisson regression: predictors of the number of residential beds in non-hospital residential facilities

\begin{tabular}{|c|c|c|c|c|c|c|}
\hline Variable & Estimate & s.e. & $Z$ & $P$ & RR & $95 \% \mathrm{Cl}$ \\
\hline Intercept & -7.680 & 0.020 & & & & \\
\hline Community mental health centres $(\times 100)$ & -0.955 & 0.148 & -6.47 & $<0.00 \mathrm{I}$ & 0.385 & $0.288-0.514$ \\
\hline Day centres $(\times 100)$ & -1.127 & 0.087 & -12.97 & $<0.001$ & 0.324 & $0.273-0.384$ \\
\hline General hospital psychiatric wards $(\times 100)$ & 0.735 & 0.194 & 3.79 & $<0.00 \mathrm{I}$ & 2.086 & $1.426-3.050$ \\
\hline Beds in private in-patient facilities $(\times 1000)$ & 0.539 & 0.025 & 21.18 & $<0.00 \mathrm{I}$ & 1.715 & $\mathrm{I} .63 \mathrm{I}-\mathrm{I} .803$ \\
\hline Day hospitals $(\times 100)$ & 0.394 & 0.095 & 4.16 & $<0.00 \mathrm{I}$ & 1.483 & $1.232-1.786$ \\
\hline Number of unemployed $\left(\times 10^{6}\right)$ & -0.303 & 0.031 & -9.73 & $<0.001$ & 0.739 & $0.695-0.785$ \\
\hline Regional income ( $€$ million) & 0.051 & 0.028 & 1.80 & 0.071 & 1.052 & $0.996-1.112$ \\
\hline
\end{tabular}

RR, relative risk.

\section{Turnover of residents}

Turnover of residents was low. During 1999, more than a third of NHRFs $(37.7 \%)$ had not discharged any patients and $31.5 \%$ had discharged only one or two (Table 2). Consequently, few new admissions were possible: $24.4 \%$ had not admitted any new residents in 1999, and $26.3 \%$ had admitted only one or two patients. The results of the multiple logistic regression analysis for 1091 NHRFs are shown in Table 3. Of the variables included in this analysis, intensity of care and type of management were not significantly associated with low turnover. The variables significantly associated with lack of discharges were the most numerous age group and the number of residents, which also showed a significant interaction. Nondischarge was inversely related to the number of residents and directly related to the mean age of residents. A first-order interaction between these variables revealed that in NHRFs in which most patients were from the oldest age group (>60 years), the probability of nondischarge was higher than in the other two age groups and was not significantly associated with the number of residents. However, in NHRFs with patients mainly from the other two age groups ( $<40$ years and 40-59 years), non-discharge was related to having more patients.

The odds for non-discharge in NHRFs hosting only former mental hospital patients was double that of the other NHRFs (95\% CI 1.56-3.35) while NHRFs without full-time staff had 1.6 times the risk of non-discharge (95\% CI 1.16-2.30) compared with the other NHRFs.

\section{NHRFs and other mental health facilities}

Table 4 shows the relationship between availability of residential places and provision of other mental health services in each region controlling for two basic socio-economic indicators (number of unemployed and overall regional income). A high rate of residential beds was associated with a higher rate of private in-patient beds, day hospitals and general hospital wards, and fewer community mental health centres and day centres, but the effect of former mental hospitals was not significant. More residential beds were found in regions with a lower number of unemployed people, but the effect of regional income was not significant (at the 5\% level). The impact of these variables on bed numbers has been quantified using 
relative risk (RR). For example, with an increase of 1000 private in-patient beds, the rate of residential beds increases by a factor of 1.7 (and similar considerations apply for other variables with $\mathrm{RR}>1$ ); with an increase of 100 in the number of community mental health centres, the rate of residential beds shows a decrease of 2.6 times $(1 / 0.385$, which is the RR for this variable; similar considerations apply for other variables with a $R R<1$ ). The regression equation predicted between-region variation in number of residential beds both in absolute and relative terms; the linear correlation coefficient between predicted and actual residential beds was 0.93 , while the correlation between predicted and current occupancy rate per 10000 inhabitants was 0.80 .

\section{DISCUSSION}

This study is the first Italian survey of residential alternatives to hospitals. To our knowledge, similar studies carried out in European countries have not exceeded the regional level (Faulkner et al, 1993; Lelliott et al, 1996). In the USA a national survey of residential care was made by the National Institute of Mental Health (Randolph et al, 1991), but only two-thirds of the agencies providing residential services participated in the study and the information was not detailed.

The NHRFs in Italy constitute a heterogeneous system which has developed in response to two basic needs: to provide alternative accommodation to mental hospitals; and to set up a network of rehabilitative facilities for younger patients with chronic disorders, drawn from the community. This system is mainly public, but with substantial subcontracting to forprofit and non-profit private agencies. It has been organised locally in response to local needs with little definition of standards of care. Our study has provided evidence of this heterogeneity, underlying the need for better classification of these facilities and establishment of national and international standards of care and staffing to be matched with patients' needs.

The current provision of non-hospital residential beds is substantially higher than the 2 per 10000 rate recommended by the Italian National Mental Health Plan (Progetto Obiettivo, 1999). However, there was a high degree of variability between regions. It seems unlikely that regional differences in prevalence of mental disorders can account for this variability. Indeed, data from five psychiatric case registers in dissimilar areas of the country did not show any notable difference in the prevalence of severe mental disorders (Balestrieri et al, 1992). There were more residential beds in regions with smaller numbers of unemployed people, and there was no correlation with regional income. Moreover, the two regions with the smallest provision of residential beds (Tuscany and Campania), respectively located in the centre and in the south, are among the richest and the poorest respectively of all 21 regions; while the two regions with the highest provision of residential beds (e.g. Abruzzo and Molise), both in central Italy, are not wealthy. Therefore, it is difficult to establish any correlation at a regional level between provision of residential beds and socio-economic indicators.

It may be concluded that, at least in part, variations in the provision of residential beds reflect regional differences in health planning (Tognoni \& Saraceno, 1989; Fioritti et al, 1997; de Girolamo \& Cozza, 2000). The inverse relationships between residential beds and communitybased facilities suggests that some regions made provisions for community care, while others merely transferred patients from hospitals to long-term residences, including private acute in-patient facilities. These differences seem consistent with a broader political trend allowing for a large degree of regional autonomy in the planning and implementation of mental health services, known as 'health devolution'.

In any event, the rate of residential beds in Italy is substantially lower than that found in the Mental Health Residential Care Study in eight districts surrounding London (9.46 beds per 10000) (Lelliott et $a l, 1996)$. However, in another UK survey of 35 districts, the rate was 4.29 , closer to the 2.98 Italian rate (Faulkner et al, 1993).

It seems difficult to establish precise standards for the provision of residential beds, since 'housing needs assessments crucially depend on the range and quality of other local services and cannot be separated from the functioning and dynamics of the total service "system", (Shepherd \& Murray, 2001).

\section{Rehabilitation centres or 'homes for life'?}

Our results suggest that many NHRFs merely provide long-term accommodation.
Lack of mobility was inversely related to the exclusive presence of former mental hospital patients and to the number of residents, while it was directly related to the age of residents. Only in NHRFs providing for older patients was low turnover unrelated to the number of patients. Since the absence of full-time staff (which suggests low intensity of care) was also related to a low turnover, it seems that NHRFs hosting more patients, predominantly elderly, and having no full-time staff to provide intensive rehabilitation, have few discharges.

Similar low turnover rates have been observed in the USA (Geller \& Fisher, 1993) and in British studies of patients discharged from mental hospitals (Trieman et al, 1998). In the Team for the Assessment of Psychiatric Services (TAPS) study, 61\% of the patients discharged to community placements (mostly group homes) remained in the same accommodation over the 5-year follow-up (Trieman et al, 1998). Despite a tendency for long-term stay in large NHRFs, it should be stressed that several studies have shown that living in small, domestic environments is associated with better quality of life and higher satisfaction reported by patients, compared with traditional mental health wards (Lehman et al, 1986; Barry \& Crosby, 1996).

\section{Staffing: quantity and quality}

Three-quarters of the NHRFs provided 24hour care, representing a real alternative to long-stay hospital wards. The ratio of patients to full-time staff of 1.42:1 gave further support to the intensive care notion of residential services in Italy. However, about $40 \%$ of staff had no specific professional qualification for working with people with severe psychiatric illness. Similar lack of trained staff caring for patients in NHRFs has been observed in the USA and the UK (Randolph et al, 1991; Senn et al, 1997). Efforts should be made to train mental health workers to treat residential patients.

\section{In-patient psychiatric care today in Italy}

In May 2000 there were 27649 psychiatric beds in Italy (including hospital and residential places). Since 1978, when Law 180 was enacted, there has been a $65 \%$ reduction in the provision of residential beds of all kinds. This change in service provision seems to have occurred without 
increases in suicide rates (Williams et al, 1986; De Leo et al, 1997) or in the number of patients admitted to psychiatric forensic facilities (Fioritti et al, 2001). Although there is no detailed information, numbers of homeless people with mental illness do not appear to have increased in urban areas (de Girolamo \& Cozza, 2000). It is also unlikely that community-based services have reduced the prevalence of serious mental disorders, as implementation of evidence-based treatment strategies has been delayed as in other countries (Falloon et al, 1999). Support for families has been provided unevenly, even though a large proportion of people with mental illness in Italy live with their families (Warner et al, 1998; Magliano et al, 2000).

Regions with better provision of outpatient and day care services had lower rates of residential beds. This suggests that providing more community services might reduce the need for residential care. However, it is also possible that the availability of more residential beds decreases the need for community-oriented services, or that a third factor has an influence on overall service provision. In any case, at a regional level, service planning has focused on developing either a caring supportive approach based on long-term residential care, or a more community-based rehabilitative treatment approach.

\section{Limitations of the study}

This study has some limitations. First, the large number of researchers collecting data might have created inconsistencies. Second, the cross-sectional design of the study does not allow causal inferences, for instance regarding the relationship between provision of NHRFs and of other types of psychiatric services.

Despite such limitations, PROGRES is the first systematic attempt in Italy to fill the gap between psychiatric services planning and evaluation, by setting up a network of investigators throughout the country and evaluating an entire typology of services in a consistent fashion.

\section{ACKNOWLEDGEMENTS}

Thanks to G. Bonaviri (Frosinone), G. Cecere (Rome), G. De Carli (Verona), G. Finizia (Verona), A. Guidi (Massa), A. Lora (Milan), G. Tibaldi (Turin), and the Centro Studi sulla Psichiatria (Turin) for their valuable collaboration. Thanks also to the following project collaborators: C. Busana, D. Casagrande, A. Citron, G. Coppola, G. Crisafulli, A. Dallaporta,

\section{CLINICAL IMPLICATIONS}

In Italy, a large number of people with severe mental illness who would have previously been treated in mental hospitals are now treated in residential facilities.

Planning of residential facilities should be preceded by a thorough evaluation of the overall network of existing services, and should ensure a continuum of care intensity.

Efforts should be targeted to improve staff training and identify key features of optimal residential care.

\section{LIMITATIONS}

The large number of researchers collecting data may have created inconsistencies.

- Detailed evidence about patients, staff and quality of care will only be available from phase 2 of the study.

- The relationship between provision of residential care and of other psychiatric services is correlational and does not imply a causal relationship.

G. DE GIROLAMO, MD, A. PICARDI, National Institute of Health, National Mental Health Programme, Rome, Italy; R. MICCIOLO, MD, Department of Biostatistics, University of Trento, Italy; I. FALLOON, MD, Department of Psychiatry, University of Aukland, New Zealand; A. FIORITTI, MD, Programme on Mental Health and Substance Abuse, Azienda ASL di Rimini, Italy; P. MOROSINI, MD, National Institute of Health, National Mental Health Programme, Rome, Italy

Correspondence: Dr G. de Girolamo, Department of Mental Health, Viale Pepoli 5, 40123 Bologna, Italy. Tel: +395I 6584377; fax: +39516584178, e-mail: gdg@iss. it

(First received 5 June 200I, final revision 10 April 2002, accepted 16 April 2002)

M. D’Arpa, M. De Palma, E. Destro, L. Filippone, S. Frazzingaro, V. Gallio, W. Gallotta, A. Giammusso, G. Gurgone, G. lonta, L. Lalicata, D. Lamonaca, A. Mengano, P. Michielin, F. Moni, G. Motta, F. Perez De Vera, F. Piazza, P. Pristinger, C. Romano, P. Roveroni, B. Sanna, A. Santarelli, G. Sapienza, G. Sciacca, S. Tartaglione, S. Testa, P. Tito, E. Toniolo, G. Zimbalatti and E. Zoccoli. Finally, T. Burns, R. Kessler, G. Shepherd and R. Warner provided helpful comments on an earlier draft of the manuscript, and G. Bignami gave invaluable input and support throughout the whole project.

\section{APPENDIX}

\section{Members of the PROGRES team}

National coordinators: Dr G. de Girolamo, Dr A Picardi, Dr P. Morosini (National Mental Health Project, National Institute of Health, Rome); biostatistician: Professor R. Micciolo (University of Trento); regional coordinators: Dr P. Argentino, Professor M. Casacchia, Dr P. Ciliberti, Dr G. Civenti, Dr A. Colotto, Dr G. Dell'Acqua, Dr P. Di lorio, Dr W. Di Munzio, Dr G. Fagnano, Dr A. Fioritti, Dr N. Longhin, Dr M. Miceli, Dr M. Nicotera, Dr M. Pisetta, Dr R. Putzolu, Dr E. Rossi, Dr M. E. Rotunno, Professor G. Borsetti, Dr D. Semisa, Dr R Tomasi, Dr P. Tulli, Dr E. Zanalda. Researchers: Dr C. Barbini,
Dr F. Basile, Dr G. Bazzacco, Dr R. Bracco, Dr A. Calvarese, Dr G. Canuso, Dr E. Caroppo, Dr L. Caserta, Dr M. Colangione, Dr S. Damiani, Dr T. De Donatis, Dr F. Di Donato, Dr V. Di Michele, Dr R. Esposito, Dr M. Facchini, Dr S. Ferraro, Dr P. Fracchiolla, Dr P. Gabriele, Dr D. Gallicchio, Dr G. Giardina, Dr A. Greco, Dr F. Grilletti, Dr S. Guzzo, Dr A. M. Lerario, Dr M. R. Marinelli, Dr C. Marino, Dr E. Monzani, Dr F. Picoco, Dr L. Pinciaroli, Dr C. A. Rossetti, Dr P. Rubatta, Dr G. Santone, Dr F. Scorpiniti, Dr V. Scrofani, Dr G. Soluri, Dr M. Stefani, Dr A. Svettini, Dr A. Vannini, Dr A. Zaffarano. Scientific consultants: Dr F. Amaddeo, Dr P. Bonizzato, Dr B. D'Avanzo, Dr G. Ditta, Professor I. Falloon

\section{REFERENCES}

Balestrieri, M., Micciolo, R., De Salvia, D., et al (1992) Confronti e prospettive nella utilizzazione dei Registri Psichiatrici dei Casi. Epidemiologia e Prevenzione, I, 133-148.

Barry, M. M. \& Crosby, C. (1996) Quality of life as an evaluative measure in assessing the impact of community care on people with long-term psychiatric disorders British Journal of Psychiatry, 168, 210-216.

Breslow, N. E. \& Day, N. E. (1980) Statistical Methods in Cancer Research. Vol. I, The Analysis of Case-Control Studies. Lyon: IARC. 
_ \& _ (1987) Statistical Methods in Cancer Research. Vol. II, The Design and Analysis of Cohort Studies. Lyon: IARC.

de Girolamo, G. \& Cozza, M. (2000) The Italian psychiatric reform: a 20 -year perspective. International Journal of Law and Psychiatry, 23, 197-214.

De Leo, D., Conforti, D. \& Carollo, G. (1997) A

century of suicide in Italy: a comparison between the old and the young. Suicide and Life-Threatening Behavior, 27. 239-249.

Falloon, I. R. H. and the Optimal Treatment Project Collaborators (1999) Optimal treatment for psychosis in an international multisite demonstration project. Psychiatric Services, 50, 615-618.

Faulkner, A., Field, V. \& Lindesay, J. (1993) Residential care provision in mental health: the current picture and future uncertainties. Journal of Mental Health, 2, 57-64.

Fioritti, A., Lo Russo, L. \& Melega, V. (1997) Reform said or done? The case of Emilia-Romagna within the Italian psychiatric context. American Journal of Psychiatry, 154, 94-98.

_ , Melega, V., Ferriani, E., et al (200I) Crime and mental illness: an investigation of three Italian forensic hospitals. Journal of Forensic Psychiatry, 12, 36-51.
Geller, J. L. \& Fisher, W. H. (1993) The linear continuum of transitional residences: debunking the myth. American Journal of Psychiatry, 150, 1070-1076.

Lehman, A. F., Possidente, S. \& Hawker, F. (1986) The quality of life of chronic patients in a State Hospita and in community residences. Hospital and Community Psychiatry, 37, 901-907.

Lelliott, P., Audini, B., Knapp, M., et al (1996) The Mental Health Residential Care Study: classification of facilities and description of residents. British Journal of Psychiatry, 169, 139-147.

Magliano, L., Fadden, G., Economou, M., et al (2000) Family burden and coping strategies in schizophrenia: I-year follow-up data from the BIOMED I study. Socia Psychiatry and Psychiatric Epidemiology, 35, 109-115.

Progetto Obiettivo (1999) Progetto Obiettivo Tutela della Salute Mentale 1998-2000. Gazzetta Ufficiale della Repubblica Italiana, 274, 4-13.

Randolph, F. L., Ridgway, P. \& Carling, P. J. (1991) Residential programs for persons with severe mental illness: a nationwide survey of state-affiliated agencies. Hospital and Community Psychiatry, 42, IIII-III5.

Senn, V., Kendal, R. \& Trieman, N. (1997) The TAPS project 38: level of training and its availability to carers within group homes in a London district. Social Psychiatry and Psychiatric Epidemiology, 32, 317-322.

Shepherd, G. \& Murray, A. (200I) Residential care. In Textbook of Community Psychiatry (eds G. Thornicroft \& G. Szmukler), p. 310. Oxford: Oxford University Press.

Tognoni, G. \& Saraceno, B. (1989) Regional analysis of implementation. International Journal of Social Psychiatry, 35, 38-45.

Trieman, N., Smith, H. E., Kendal, R., et al (1998) The TAPS project 4I: homes for life? Residential stability five years after hospital discharge. Community Mental Health Journal, 34, 407-417.

Warner, R., de Girolamo, G., Belelli, G., et al (1998) Quality of life and psychopathology in Boulder, Colorado, and Bologna, Italy. Schizophrenia Bulletin, 24 559-568.

Williams, P., De Salvia, D. \& Tansella, M. (1986) Suicide, psychiatric reform, and the provision of psychiatric services in Italy. Social Psychiatry, 2I, 89-95.

Zheng, B. \& Agresti, A. (2000) Summarizing the predictive power of a generalized linear model. Statistics in Medicine, 19, |77|-1781. 